ESPAÇO TEMATICO - SERVIÇO SOCIAL: FORMAÇÃO, TRABALHO POFISSIONAL E

TENDÊNCIAS TEÓRICAS CONTEMPORÂNEAS

\title{
Educação a distância e formação profissional do/da assistente social: elementos para o debate
}

\author{
Patrícia Palmeira Gonçalves ${ }^{1}$ \\ https://orcid.org/0000-0002-2450-4145
}

\author{
Claudia Neves da Silva ${ }^{2}$ \\ https://orcid.org/0000-0003-1337-4741
}

${ }^{1}$ Prefeitura Municipal de Londrina, Secretaria Municipal de Assistência Social, PR, Brasil

${ }^{2}$ Universidade Estadual de Londrina, Departamento de Serviço Social, Programa de Pós-Graduação em Serviço Social e Política Social, PR, Brasil

\section{Educação a distância e formação profisssional do/da assistente social: elementos para o debate}

Resumo: Este artigo tem por objetivo analisar em que medida a formação em Serviço Social a distância se fundamenta ou se distancia dos princípios das diretrizes curriculares da Associação Brasileira de Ensino e Pesquisa em Serviço Social (ABEPSS) de 1996. O Ensino a Distância está previsto na política educacional de ensino superior no Brasil e se caracteriza pela mercantilização e por um discurso de democratização que escamoteia a precarização do ensino. Não temos por intenção fazer críticas ou julgamentos em relação aos trabalhadores ou estudantes desta modalidade. Verificamos que o ensino a distância tem se operacionalizado como ensino de massa e a padronização e a tecnologia como mediador principal submete os trabalhadores à alienação do trabalho. Esse é um determinante do processo formativo nessa modalidade. Outras características levantadas foram, a superficialidade do material apostilado, que não contempla o rigor teórico-metodológico preconizado pelas diretrizes da Associação Brasileira de Ensino e Pesquisa em Serviço Social e a inexistência do tripé ensino-pesquisa-extensão.

Palavras-chave: Serviço Social. Diretrizes Curriculares. Ensino a Distância. Associação Brasileira de Ensino e Pesquisa em Serviço Social.

\section{Distance Learning and Social Workers' Professional Education: Elements for Debate}

Abstract: The purpose of this article is to analyze the extent to which distance social work training is based on or distant from the principles of the ABEPSS curriculum guidelines of 1996. We set out to analyze educational policy based on the framework we have adopted, distance education policy in Brazil, characterized by excessive commercialization and a discourse of democratization that eschews the precariousness of teaching, and does not expose or criticize the workers or students who work and study in this modality, that "motivates" the subjects to act in this modality is the material reproduction of the daily life. We have verified that distance education has been operationalized as mass education. Standardization and technology as the main mediator subjects workers to alienation at work. This is a determinant of the formative process in this modality. Other characteristics raised were the superficiality of the apostilled material, which does not contemplate the theoretical - methodological rigor advocated by ABEPSS guidelines and the inexistence of the tripod research - teaching and extension.

Keywords: Social Work. Curricular Guidelines. Distance learning. ABEPSS.

Recebido em 30.06.2019. Aprovado em 17.09.2019. Revisado em 20.11.2019.

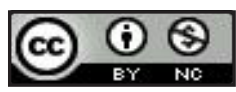

C) O(s) Autor(es). 2020 Acesso Aberto Esta obra está licenciada sob os termos da Licença Creative Commons Atribuição-NãoComercial 4.0 Internacional (https://creativecommons.org/licenses/by-nc/4.0/deed.pt_BR), que permite copiar, distribuir e reproduzir em qualquer meio, bem como adaptar, transformar e criar a partir deste material, desde que para fins não comerciais e que você forneça o devido crédito aos autores e a fonte, insira um link para a Licença Creative Commons e indique se mudanças foram feitas. 


\section{Introdução}

O interesse pelo Ensino à Distância $(\mathrm{EaD})$ no Serviço Social surgiu após participação e vivência no conjunto Conselho Federal de Serviço Social (CFESS)/Conselho Regional de Serviço Social (CRESS)da Seccional de Londrina, na gestão de 2014-2017. O tema nos chamou a atenção por ser um assunto sobre o qual o conjunto tem tratado com frequência e por residir em uma região onde existe uma instituição que oferece o curso de Serviço Social a distância.

O fato de residir e estudar na cidade onde há, atualmente, a coordenação do maior grupo educacional em $\mathrm{EaD}$, de certa forma funcionou como um facilitador no que diz respeito a acessar as/os profissionais que trabalham nesta modalidade de ensino, e um dificultador, por ter um grande número de assistentes sociais da região que são trabalhadores do ensino a distância, como tutores ou professores, e por vezes não se sentirem à vontade para tratar do assunto, por receio de sofrer algum preconceito ou represália por parte da instituição.

O motivo que nos levou a estudar essa modalidade de ensino é a preocupação com a formação e o exercício profissional do/da assistente social, tendo em vista que pelas pesquisas realizadas por Pereira (2012), na última década esta modalidade teve grande crescimento, o que provocará mudanças no perfil dos/das assistentes sociais nos próximos anos.

Acreditamos que à medida que ampliarmos o debate, trazendo cada vez mais para a concretude do cotidiano, poderemos avançar no sentido da formação que a categoria profissional deseja, através do projeto profissional que foi construído no decorrer desses oitenta anos - 1936/2019. Assim, temos por objetivo analisar em que medida a formação em serviço social a distância se fundamenta ou se distancia dos princípios das diretrizes curriculares da ABEPSS de 1996.

Os sujeitos que fizeram parte do universo da pesquisa são professores, tutores e aluno do ensino a distância que trabalharam e estudaram respectivamente na instituição de ensino superior a distância. Para evitar constrangimento ou retaliação da instituição de ensino aos sujeitos da pesquisa, decidimos por selecionar àqueles que já se desligaram da instituição, não os identificar pelo nome e não identificar o período que trabalharam na instituição. Nossa amostra constituiu-se de 1 (um) professor, dois tutores e 1 (um) estudante ${ }^{1}$.

Para a realização da análise dos dados coletados, elegemos como parâmetro as diretrizes curriculares da Associação Brasileira de Ensino e Pesquisa em Serviço Social (ABEPSS), publicadas no ano de 1996. Afinal, as diretrizes são frutos de um processo histórico de amplo debate entre as instituições de ensino de Serviço Social, cujo objetivo foi definir o perfil profissional que se deseja formar, a partir do acúmulo teóricometodológico, técnico-operativo e ético-político realizado na profissão.

\section{As orientações dos organismos internacionais para o ensino superior brasileiro}

Nas últimas décadas, os sujeitos políticos coletivos do capital - Grupo Banco Mundial (BM), Organização das Nações Unidas para Educação, Ciência e Cultura (UNESCO) e, mais recentemente, a Organização Mundial do Comércio (OMC) "vêm promovendo e orientando um conjunto de reformas econômicas e políticas para os países da periferia do capitalismo (LIMA, 2007). Nesse conjunto de contrarreformas estão inseridas as reformas educacionais, cuja premissa é a de que o acesso à capacitação é o passaporte para a empregabilidade e o desenvolvimento.

A privatização dos serviços públicos, incluindo a política de educação, principalmente a educação superior nos países da periferia do capitalismo se daria, segundo Lima (2007), através de dois processos norteadores: a diversificação das instituições de ensino superior (IES) e dos cursos e a diversificação das fontes de financiamento. Esses eixos e orientações estão presentes no documento $O$ ensino superior: as lições derivadas da experiência (BANCO MUNDIAL, 1994).

Neste documento estão expressas as estratégias para a reforma da educação superior na América Latina, Ásia e Caribe. A estratégia de diversificação das instituições e dos cursos de ensino superior, sob o pressuposto do desenvolvimento de universidades públicas, privadas e de instituições não universitárias, se concentra principalmente em cursos politécnicos e de curta duração, direcionados para trabalhadores e filhos de trabalhadores.

O documento também destaca o Ensino a Distância, que "[...] pode ser eficaz para aumentar, a um custo moderado, o acesso dos grupos desfavorecidos, que em geral estão deficientemente representados entre os estudantes universitários" (BANCO MUNDIAL, 1994, p. 36).

No Brasil, as mudanças na educação superior foram consubstanciadas na Lei de Diretrizes e Bases da Educação (LDB-96). O capítulo sobre educação superior da LDB, segundo Sguissardi e Silva Júnior (1999), é uma espécie de plataforma legal a dar guarida presente e futura à série de ações de reforma que se fundamen- 
tam em princípios defendidos tanto por organismos supranacionais, como o Banco Mundial, quanto por analistas e mentores nacionais da modernização do sistema de educação superior no País.

Ainda de acordo com Sguissardi e Silva Júnior (1999), a associação de ensino, pesquisa e extensão (modelo humboldtiano) deveria estar restrita a algumas instituições universitárias, com a maioria dedicando-se apenas ao ensino; não obstante a Lei n. 5.540 de 1968 preconizar o modelo humboldtiano das universidades de pesquisa, a realidade se apresentava de forma diferente: na década de 1990-das quase 900 instituições de ensino superior existentes no país, apenas 140 estavam organizadas como universidades, sendo as demais instituições isoladas e excepcionalmente desenvolvendo pesquisas (SGUISSARDI; SILVA JÚNIOR, 1999).

\section{[...] pelos depoimentos dos} entrevistados há um esvaziamento da função docente no processo de supervisão, fundamental para que o discente possa realizar a mediação entre os aportes teóricos desenvolvidos na formação e a prática do estágio, não atendendo desta forma o que está disposto nas Diretrizes Curriculares [...]

Dentre as metas estabelecidas pelo Plano Nacional de Educação (2001-2011), além da meta de ampliar em 30\% o acesso de jovens de 18 e 24 anos ao ensino superior, havia a meta de "Estabelecer um amplo sistema interativo de educação a distância, utilizando-o, inclusive, para ampliar as possibilidades de atendimento nos cursos presenciais, regulares ou de educação continuada" (BRASIL, 2001). A LDB já havia dado chancela legal a essa modalidade de educação e o PNE enfatizava sua utilização.

O Brasil, a partir da década de 1990, apresentou uma intensa mercantilização do ensino superior, por meio da abertura de muitas vagas em cursos de instituições de ensino de caráter não universitário, além do incentivo ao ensino a distância. O que atingiu também o curso de Serviço Social.

Sguissardi (2015) revela que o Brasil foi pioneiro na abertura de capital de empresas educacionais que fazem oferta pública inicial (IPO) na Bolsa de Valores de São Paulo (Bovespa). As quatro primeiras empresas educacionais a fazê-lo foram Kroton, Estácio, Anhanguera e SEB - Sistema Educacional Brasileiro ou Colégio Oswaldo Cruz, Dom Bosco e Pueri Domus, no ano de 2007.

Das empresas que possuem capital aberto na Bolsa de Valores, praticamente todas tiveram ou têm participação acionária de fundos de investimentos, em geral transnacionais. Entre os cincos maiores grupos " Estácio, Unip, Anhanguera, Kroton e Laurete - somente a Unip não tem a presença do setor financeiro na sua administração. A Universidade Estácio de Sá é administrada pelo fundo GP; a Anhanguera pelo Banco Pátria; a Kroton pela Advent Internacional, e a Laurete pelo fundo americano KKR (SGUISSARDI, 2015, p. 872).

A abertura de capital dessas empresas ao mercado de ações e a valorização destas últimas possibilitam o aumento de seu capital, a compra de outras instituições menores espalhadas pelo país e a formação de grandes grupos empresariais, também denominados "redes". (SGUISSARDI, 2015, p. 872).

\section{O Ensino a distância e o Serviço Social}

Como resultado da adesão dos governos brasileiros à pauta neoliberal, a partir do governo Fernando Henrique Cardoso e nos governos Lula da Silva e Dilma Roussef, a educação superior brasileira foi cada vez mais sendo ofertada por instituições de ensino superior privado, além do uso do fundo público para custear vagas nestas instituições privadas através de programas como o Fundo de Financiamento Estudantil (FIES) e o Programa Universidade para Todos (PROUNI).

A situação nos cursos de Serviço Social não foi diferente, nos anos 1990 ocorreu uma grande expansão, em sua maioria em instituições de ensino privadas. Segundo dados colhidos por Lima e Pereira (2009, p. 43): "No âmbito do Serviço Social, entre 1995 e 2002, foram criados mais 50 cursos, sendo 90\% através da iniciativa do setor privado".

No Governo de Luís Inácio Lula da Silva (2003-2010), além da expansão do ensino privado iniciou-se uma outra modalidade de formação no ano de 2006, a educação a distância, e o que nos interessa, a criação de cursos de Serviço Social na modalidade de Educação a Distância (EaD), com 11 instituições oferecendo o curso nesta modalidade (LIMA; PEREIRA, 2009, p. 45). 
Como no Serviço Social a modalidade de ensino começou a funcionar em 2006, ainda há poucas pesquisas a respeito desta modalidade. Larissa D. Pereira $(2012$, p.38) fez estudos pioneiros nessa área trazendo um panorama inicial "até junho de 2011, a base de dados do Sistema e-MEC apresenta a existência de 14 Instituições de Ensino Superior (IES) que ofertam cursos de Serviço Social a Distância em municípios espalhados por todo país, totalizando 56.651 vagas anuais".

Quanto às titulações de coordenadores dos cursos, a referida pesquisadora afirma que somente duas das coordenações das 14 IES possuíam titulação de Doutorado. Com relação à produção acadêmica dos coordenadores dos cursos, todas demonstraram fragilidade de inserção em atividades de pesquisa.

A partir desses dados, Pereira (2012 p. 43) destaca que o discurso de 'democratização do acesso ao ensino superior', na verdade demonstra a criação de uma dualidade no acesso, ou seja, para os trabalhadores empobrecidos o EaD e cursos privados mais baratos e "para as elites e camadas médias altas, uma educação nas universidades públicas federais ou estaduais ou nas instituições privadas de alto prestígio social, como as católicas".

No que se refere à direção curricular, até 1996 o ensino no Serviço Social se respaldava em currículos mínimos. A alteração para diretrizes curriculares ocorreu a partir de algumas resoluções do Ministério da Educação e Cultura (MEC) e do Conselho Nacional de Educação (CNE), que, conforme indica Portes (2016, p. 61), estabeleceram para todos os cursos de graduação um modelo de enquadramento das propostas de Diretrizes Curriculares Nacionais, apresentando um roteiro de natureza metodológica para construção dessa proposta.

A ABEPSS apresentou um documento - Diretrizes Gerais para o Curso de Serviço Social " em que expressava, entre outras preocupações, a necessidade de propor uma base curricular que superasse a fragmentação do processo ensino-aprendizagem possibilitando uma maior convivência entre professor, discente e a comunidade (ASSOCIAÇÃO BRASILEIRA DE ENSINO E PESQUISA EM SERVIÇO SOCIAL, 1996).

Contudo, a Lei de Diretrizes e Bases da Educação (1996) trazia uma importante ruptura no planejamento do ensino superior, e as principais alterações estavam relacionadas à autonomia universitária, ao fim dos currículos mínimos e à inclusão de uma nova modalidade de ensino superior (LEWGOY; MACIEL, 2016). Conforme as autoras (LEWGOY; MACIEL, 2016), as alterações provocaram um atraso na implementação e execução das Diretrizes, porque somente foi aprovado em 2012.

Não obstante, a direção dada pelo MEC e o CNE às Diretrizes Curriculares do curso de Serviço Social, as universidade públicas e algumas universidades particulares mantiveram a direção social do projeto de formação profissional do Serviço Social, com a perspectiva assumida na década de 1980 de vinculação aos interesses da classe trabalhadora, reafirmado também pelo Código de Ética Profissional de 1993 (CARDOSO, 2000).

Seguindo essa perspectiva, a partir do Código de Ética e das Diretrizes Curriculares da ABPESS, estudamos as condições de trabalho no ensino a distância, a supervisão de estágio, a orientação do trabalho de conclusão de curso, a efetivação do tripé ensino-pesquisa-extensão e como se dá o repasse de conteúdo.

\section{As condições de trabalho no Ensino a Distância}

Antes de prosseguirmos, é importante esclarecer que nosso foco de estudo é o curso de Serviço Social na modalidade $\mathrm{EaD}$, nomeadamente se os estudantes do curso têm acesso à formação profissional preconizada pelas Diretrizes Curriculares da ABEPSS. Não temos por intenção criticar, estigmatizar ou denunciar os docentes e estudantes desta modalidade. Para tanto, não apresentamos as características que possam identificar o professor, os dois tutores e o estudante que fizeram parte de nossa amostra, como idade, período em que trabalharam/estudaram na instituição bem como o nome das disciplinas que lecionaram. São provenientes de um mesmo grupo educacional e não possuem mais vínculo com a instituição "na vigência do contrato de trabalho ou de estudo, tinham que respeitar as obrigações contratuais e submeterem sua participação em alguma pesquisa à prévia autorização da instituição.

A opção por estudar esse tema em uma cidade na qual há muitos trabalhadores assistentes sociais atuando nessa modalidade de ensino implicou em algumas situações delicadas, o que mostrou que precisamos avançar no sentido de ter um diálogo mais amplo sobre a modalidade de ensino no Serviço Social, sem que os sujeitos se sintam culpabilizados, tendo em vista que, como o estudante expôs, por diversas vezes sentiu preconceito da categoria em relação à sua formação. Contudo, por sua condição de aluno-trabalhador foi a opção viável para aquele momento de sua vida.

Nas entrevistas realizadas com o professor e os tutores identificamos uma sobrecarga de trabalho e a inexistência de treinamento referente ao conteúdo do Serviço Social. Almeida e Wolff (2008) afirmam que com a automação das aulas, há uma desvalorização e simplificação do trabalho docente, em virtude deste trabalho ficar subordinado ao manejo do aparato tecnológico, além do professor ser levado a buscar novas aptidões 
exigidas pelo aparato tecnológico, deixando de lado outros aspectos de sua formação - situação que também observamos em nossa pesquisa.

O professor entrevistado trabalhou em uma instituição pertencente ao grupo Kroton. Esta instituição era totalmente voltada à modalidade a distância, não ocorrendo aulas presencias. $\mathrm{O}$ trabalhador esclarece que por esse motivo a fase era de adaptação e na época trabalhava a partir do material produzido por outros profissionais, fato que reconhece ter sido um dificultador.

Os outros entrevistados trabalharam em instituição de ensino superior privada com sede no Paraná e que também foram adquiridas pelo grupo Kroton. Esta instituição tinha como característica ser semipresencial, ou seja, os discentes tinham momentos presenciais nos polos.

Os trabalhadores afirmaram que necessitavam do emprego para arcar com as despesas que tinham para se manterem e sobreviverem. Todos foram solícitos para exporem seu ponto de vista sobre as fragilidades dessa modalidade, pois consideraram que essa seria uma possibilidade de contribuir com o debate sobre $\mathrm{EaD}$ e com a categoria:

[...] eu estive lá dentro, e assim, e eu saí também por uma questão de que não dá, o salário é importante? É!; Está fazendo falta pra mim? Pra caramba! Isso eu não posso desconsiderar e não vou ser hipócrita, não. Fui por acreditar na formação? Não. Fui por causa de salário... então assim, tenho que me manter [...] eu já dei aula no presencial, e a minha intenção é voltar pro presencial, e é anos luz diferente, então assim, não dá pra você defender algo publicamente e fazer algo que você não acredita. (Professor).

A gente tem diversos profissionais que na verdade tão fazendo isso como forma de complementar a renda, assim, hoje eu vendendo lingerie como forma de complementar a renda, sem estressar minha cabeça eu percebo que vale muito mais a pena, afinal das contas eu consigo tirar por mês o que um profissional fazendo EaD tira, sem ter o mesmo estresse, sem ter os mesmos conflitos ideológicos que eu tinha dentro de mim, sabe? (Tutor 1).

No que se refere às condições de trabalho, há algumas divergências; o tutor 1 relatou que as condições de trabalho não eram boas, pois, às vezes, faltava o principal instrumento de trabalho, o computador, e o espaço físico era adaptado. Também relatou que sentiu cobrança da coordenação. O professor também informou que as condições físicas não eram boas, o espaço era adaptado e a Internet falhava; contudo, a postura da coordenação na sua opinião era adequada e coerente. $\mathrm{O}$ tutor 2 relatou que as condições de trabalho eram adequadas e acredita que isso decorre por ser uma instituição privada, e não destacou a ação da coordenação.

Inferimos que a diferença de opiniões decorre do fato de terem atuado em épocas diferentes, ocorrendo alterações na coordenação, no espaço físico e institucional- a instituição foi comprada pelo grupo Kroton e passou por reestruturações - além de adaptações às exigências do Ministério da Educação. Sobre a atividade de tutoria os entrevistados apontaram:

[...] Ela é mais uma função administrativa. Ele fica como um mediador entre a instituição e o aluno. Essa mediação acontece através de e-mails ou fóruns de debate no sistema on-line, que eles chamam de ambiente virtual. Então têm alguns fóruns que o tutor vai respondendo dúvidas do aluno, ou e-mail quando o aluno manda direcionado para o tutor mesmo. (Tutor 2).

O entrevistado aponta que há uma intensa estratificação de funções, isto é, cada profissional fica com uma atividade, não ocorrendo um diálogo entre professor e tutor. Outra questão importante levantada pelos profissionais é o volume de trabalho "o número de correções de provas e trabalhos passa dos 200 e chega até 800 alunos, fato que demonstra que os profissionais estão submetidos a uma demanda de trabalho excessiva:

Tinha vezes que a gente tinha 300, 400 alunos, não tem como corrigir com qualidade todas essas provas. [...] Só que você está lá no décimo, você ainda está animada, no vigésimo já está mais ou menos, a hora que chega no quinquagésimo no centésimo, você tá assim, nossa eu não dou mais conta! (Tutor1).

Os tutores relatam que a especificidade da formação não tem tanto peso no trabalho: o tutor 1 informa que na época que atuou na instituição corrigia trabalhos de disciplinas diferentes das privativas ao Serviço Social e que por mais que houvesse um "gabarito" prévio, o profissional não se sentia à vontade para corrigir trabalhos de outras áreas do conhecimento.

O tutor 2 também afirma que as atividades não exigiam muito da especificidade do assistente social. Estes relatos reforçam a análise de Peters (2006), que relaciona o ensino a distância a um ensino industrial, como ocorre 
no Fordismo, assim como a objetificação da formação, tirando o elemento "subjetivo" do ensino presencial, ou seja, a subjetividade do professor. Como o tutor2 retratou, ele se sentia fazendo uma parte do trabalho, mas não tinha relação com os outros profissionais para poder atuar sobre o processo ensino-aprendizagem.

Sobre treinamento no trabalho, todos informaram que este se foca somente no manejo do sistema, demonstrando o que Almeida e Wolff (2008) indicaram, ou seja, nessa modalidade de ensino as habilidades operacionais são valorizadas, tendo em vista que há uma automatização do exercício profissional dos professores. Como pudemos verificar o ensino a distância é um sistema massificado que visa atender uma grande quantidade de estudantes:

Quando eu entrei lá na instituição não teve capacitação, eu me lembro quê que a gente fazia, a gente se apegava aos tutores mais antigos eles que ensinavam a gente a entrar no sistema, conectar à Internet eles que ensinavam como corrigia, sabe? O que você tinha que cobrar o que você não tinha, então você acabava indo por quem estava trabalhando ali, sabe? (Tutor 2).

[...] Nós passávamos sempre por qualificação, uma ou outra pro sistema. Tipo quando colocaram uma plataforma nova de cadastramento de prova, a gente teve uma capacitação, a gente teve sempre, tem um suporte nessa questão operacional. (Professor).

Com relação à supervisão de estágio, os sujeitos entrevistados relataram que a maior fragilidade era a supervisão acadêmica, feita pelo tutor eletrônico e limitada a questões burocráticas, como a cobrança de documentação. O tutor 1 relata que apesar de não ter participado do processo, observa a diferença do que é feito em cursos de universidades públicas, onde, segundo seu relato, os professores acompanham de perto e auxiliam os supervisores de campo. Sua observação decorre de sua experiência como supervisor de campo de estágio de instituição pública.

O aluno relatou que era possível fazer a supervisão acadêmica, desde que agendasse com o professor:

Eu não cheguei a participar do processo, assim, eu sei que a que também era da Universidade, ela supervisionava estágio, eu sei que tem, mas assim, até isso também é muito diferente porque a gente teve uma colega lá que teve estagiário, dai eu lembro que assim, era dois meses de estágio, sabe? (Tutor 1).

O professor informa que a supervisão acadêmica também se limitava às questões documentais:

Quem realizava a supervisão acadêmica também é o tutor, é o tutor que realiza, existe a coordenação de estágio, que dá conta do estágio no Brasil inteiro, é uma coordenação de estágio para o Brasil todo e aí, os supervisores acadêmicos são os tutores. [...] na realidade o supervisor acadêmico ele acaba ficando mais na questão burocrática, quando os alunos vão entregar a documentação. Que aí, se faltar assinatu$\mathrm{ra}$, se faltar carimbo, a orientação é não aceitar, e não aceita, o aluno reprova e vai ter que cumprir de novo seis meses. E assim, são trezentos, quatrocentos estagiários por tutor. (Professor).

Quanto à tutoria de campo não é possível apresentar elementos, visto que não entrevistamos supervisor de campo que supervisionou estagiário das instituições.

Lewgoy (2010) destaca como instrumentos articuladores do processo de supervisão acadêmica e de campo em Serviço Social o Código de Ética Profissional (1993), a Lei de Regulamentação da Profissão (8662/ 93) e as Diretrizes Curriculares (1996); e o docente tem uma função mediadora realizada no processo de apropriação dos resultados da prática social. O objetivo deste aparato jurídico-político-organizativo é construir uma proposta pedagógica que supere a fragmentação do processo de ensino e aprendizagem permitindo intensa convivência acadêmica entre professores, alunos e sociedade.

No entanto, pelos depoimentos dos entrevistados há um esvaziamento da função docente no processo de supervisão, fundamental para que o discente possa realizar a mediação entre os aportes teóricos desenvolvidos na formação e a prática do estágio, não atendendo desta forma o que está disposto nas Diretrizes Curriculares: "Esta supervisão será feita pelo professor supervisor e pelo profissional de campo, através da reflexão, acompanhamento e sistematização [...]”. (ASSOCIAÇÃO BRASILEIRA DE ENSINO E PESQUISA EM SERVIÇO SOCIAL, 1996, p.19).

Quanto à existência de projetos de pesquisa, extensão e ensino, os sujeitos da pesquisa relataram que não tinham conhecimento de projeto de pesquisa desenvolvido pela instituição. O estudante destacou que chegou a questionar a instituição sobre essa situação, já que pela instituição se denominar Universidade, considerou que deveria desenvolver projetos de pesquisa; mas foi informado de que não havia nenhum em funcionamento. 
Um tutor e o professor destacaram que nunca participaram de projeto de extensão ou de pesquisa, mas tiveram conhecimento de que a instituição havia executado alguns projetos de extensão para garantir campo de estágio para os alunos, contrariando um dos princípios defendidos pela ABEPSS, qual seja, uma formação profissional que garanta a indissociabilidade entre ensino-pesquisa-extensão:

De pesquisa não conheci. Tinha projeto de extensão, para garantir que os alunos entrassem em campo de estágio, porque dependendo da cidade, não tem campo de estágio, dependendo da cidade a gente tem a realidade de vários profissionais não quererem mais estagiário porque demanda trabalho. (Professor).

Eu não sei se hoje tem (projeto de pesquisa ou extensão). Mas como a gente sabe que a qualidade tá decaindo então, se na época que eu entrei não tinha, agora menos ainda. E até fui orientada de falar com professores pra ver se professores não queriam montar grupo de estudos, mas a gente sabe que não é assim. (Aluno).

A ausência de projetos de pesquisa e extensão fere um dos princípios da formação idealizada pela ABEPSS, que seria uma formação que garantisse o tripé ensino, pesquisa e extensão: "Estabelecimento das dimensões investigativa e interventiva como princípios formativos e condição central da formação profissional, e da relação teoria e realidade". (ASSOCIAÇÃO BRASILEIRA DE ENSINO E PESQUISA EM SERVIÇO SOCIAL,1996, p. 6). Fere também o que está determinado no Art. 207 da Constituição Federal: "As universidades gozam de autonomia didático-científica, administrativa e de gestão financeira e patrimonial, e obedecerão ao princípio de indissociabilidade entre ensino, pesquisa e extensão". (BRASIL, 1988, p.128).

Quando nos voltamos para o trabalho de conclusão de curso, o disposto nas Diretrizes Curriculares da ABEPSS afirma que é atividade integradora do currículo que:

Deve ser entendido como um momento de sintese e expressão da totalidade da formação profissional. [...]. Realiza-se dentro de padrões e exigências metodológicas e acadêmico-científicas. Portanto, o TCC se constitui numa monografia científica elaborada sob a orientação de um professor e avaliada por banca examinadora. (ASSOCIAÇÃO BRASILEIRA DE ENSINO E PESQUISA EM SERVIÇO SOCIAL, 1996, p.19, grifo nosso).

Pelo relato dos entrevistados, há um empobrecimento do processo investigativo na formação a distância. $\mathrm{O}$ tutor 2 informa que não percebeu uma preocupação com o método científico durante os trabalhos apresentados pelos alunos; atribui esta situação à sobrecarga de trabalho dos tutores eletrônicos, que faz com que alguns tomem a decisão de deixar de orientar os estudantes. Os demais informantes nos relataram o seguinte:

Eu não fazia, quem faz orientação de TCC é o tutor. é ele que acompanha, a gente faz a proposta da construção do projeto, a gente faz a proposta de construção da forma de orientação, de como tem que ser o primeiro capítulo, o segundo, o terceiro, né? [...] e a orientação expressa é que não faça pesquisa com seres humanos, porque, assim, a instituição tinha muito medo em relação as questões éticas na pesquisa, né? Então assim, era um cuidado que eles tinham por que depois podia ter processo, essas coisas, [...] é só pesquisa bibliográfica e quem acompanha são os tutores, então tem tutor lá que tem 400 TCCs pra corrigir, pra acompanhar a orientação e corrigir. (Professor).

Quando eu fui fazer o TCC eu montei um projeto de pesquisa lá que ia ser entrevistar as pessoas, né? Eu queria fazer pesquisa e eu não fui autorizada na Universidade. De nenhuma maneira você é autorizado a fazer pesquisa de campo, nenhuma. Eu lembro que na época me explicaram que era porque na Universidade não tinha comitê de ética. (Aluno).

Os entrevistados são unânimes em apontar o número de trabalhos que os tutores têm que orientar, que, segundo os relatos, chegam a 200 trabalhos em média, tanto o tutor 1 como o estudante apontam não ser possível orientar com qualidade tantos trabalhos. Como podemos verificar, o trabalho é realizado muito mais como cumprimento de uma exigência legal, já que é obrigatório, conforme as diretrizes do MEC, do que como um trabalho que sintetiza o processo formativo, que possibilite ao discente elaborar uma análise da realidade a partir de uma fundamentação teórica, dando os primeiros passos para um processo investigativo de conhecimento de realidade.

Quanto ao conteúdo trabalhado nos cursos, o professor observa que há uma separação entre os que escrevem o material didático, os que ministram a aula online e os que produzem os desafios profissionais e provas. Mais uma vez, constatamos a forma fordista de organização do trabalho, causando a alienação dos 
trabalhadores/professores, assim como possível desorientação teórica entre os estudantes, pois há a elaboração de vários "produtos" diferentes sobre um determinado assunto.

O ensino a distância tem sido fomentado por diferentes governos para aumentar o número de matrículas de estudantes no ensino superior. Este ensino tem sido ofertado por grandes oligopólios educacionais que baseiam o modelo de ensino em uma forma massificada, padronizada e estratificada que visa pouco investimento e alta margem de lucro:

[...] tem um espaço lá que é pros alunos fazerem perguntas...só que você tem tipo mil alunos assistindo aula de uma vez você não consegue contemplar a pergunta de todas as alunas. Você não consegue garantir que quem tá dentro da sala de aula domine aquele assunto que está sendo tratado. (Tutor1).

[...] a gente tinha algumas atividades que a gente fazia em casa, virtual, né? Pela Internet e também uma vez por semana a gente tinha uma aula presencial, ai essa aula presencial ela tinha dois momentos, o primeiro momento era... eles chamavam de atividade, mas era uma atividade que o professor passava um texto ou algum exercício pra gente fazer em grupo na sala de aula então, normalmente era um texto que eles passavam e nessas duas primeiras aulas a gente discutia esses textos no grupo da sala de aula e depois vinha a aula transmitida.(Aluno).

Os estudantes têm aula ao vivo apenas uma vez por semana, sendo difícil aprofundar em algum tema com essa carga horária. A questão da distância entre os estudantes e professores que ministram as aulas foi levantada por todos os sujeitos entrevistados. Relatam que apesar de serem profissionais comprometidos percebem que a instituição não apresenta compromisso com a formação de qualidade. Constatam que a forma pela qual a instituição organiza o processo de trabalho dificulta que se faça uma formação de qualidade.

O professor destaca o episódio em que a instituição de ensino publicou em sua rede social que a "profissão de assistência social" se destinava à ajuda ao próximo, confundindo a profissão com a política pública de assistência e vinculando a profissão à caridade, ajuda e assistencialismo, perspectiva historicamente superada pela profissão. Esta situação reforça a distância entre o que foi preconizado pelas Diretrizes Curriculares da ABEPSS de 1996, como podemos verificar nas falas dos sujeitos da pesquisa:

Por mais que a gente reconheça que é uma realidade o ensino a distância, a gente reconhece que os profissionais estão se formando, tirando o registro, passando em concursos, sim a gente reconhece, não tem como burlar, é uma lei nacional, mas aí eu acho difícil quando a gente fala já que taí vamos tentar qualificar, não dá pra qualificar algo que não quer ser qualificado, porque pra você qualificar você tem que investir, investir em quem? [...] É fazer projeto de pesquisa, é fazer projeto de extensão, é gastar dinheiro para colocar em operacionalização essas diretrizes curriculares. Isso não tem. Então assim, você não pode indicar livros novos, porque eles não vão adquirir os livros novos e isso não vai ter na biblioteca. (Professor).

[...] mas os professores eles estudavam porque muito tempo a gente ficou junto dos professores né? Eles estudavam preparavam discutiam, né? A carga horária deles era maior que a nossa. Eles trabalhavam à tarde e de noite, então tinha uma preocupação deles ali agora dizer que isso partia da instituição eu acredito que não. (Tutor2).

As Diretrizes Curriculares elaboradas pela ABEPSS sofreram alterações quando aprovadas pelo MEC, principalmente na direção social da formação. As Diretrizes do MEC têm força de lei e as Diretrizes da ABEPSS são uma orientação construída pela categoria profissional a partir de sua maturidade intelectual e compromisso ético-político alinhados com a teoria social crítica para compreensão e análise da realidade social. Contudo, os sujeitos pesquisados relataram que apesar de atenderem as exigências das diretrizes do MEC, o ensino a distância não consegue contemplar o que determina as diretrizes curriculares da ABEPSS:

Eu acho que as diretrizes curriculares, o conteúdo das disciplinas, acho que segue a proposta do MEC da ABEPSS e tal, até porque eles correm o risco de perder a possibilidade de ter o curso, mas daí a fazer isso com qualidade, não acredito que eles consigam. (Tutor 1).

Eles seguem as diretrizes do MEC, e por seguir as diretrizes do MEC eles não têm a mesma profundidade e rigor teórico, trato teórico, por exemplo, nas discussões que pra gente é central, de trabalho, de questão social, de fundamentos da própria política social, isso não tem, ela tem mais uma dimensão operacional. (Professor). 
[...] O professor às vezes até tenta realmente você percebe, a gente que tem uma formação mais crítica percebe uma fala do professor que seria entendivel pra gente mas que o aluno não dá conta mesmo, sabe? São pessoas de formações muito diferentes de caminhares muito diferentes, né?(Tutor 2).

Por mais que a gente tenha um monte de atividade, e tinha mesmo, muita atividade pra fazer em casa online mesmo tendo essas aulas não é suficiente. Da mesma maneira como eu também não acho suficientes os quatro anos na presencial para esse objetivo que a ABEPSS coloca, sabe? (Aluno).

A partir das falas dos entrevistados, testemunhamos a chancela e o incentivo do Estado ao ensino a distância, com a consequente desobrigação para atender o que determina a Constituição de 1988. Neste sentido, o número de Assistentes Sociais formados na modalidade EaD cresce a cada ano, provocando mudanças no perfil dos profissionais, tendo em vista que o percurso teórico e metodológico se diferencia do preconizado pela ABEPSS. Fica-nos uma indagação: como a ABEPSS e os demais órgãos da categoria estão se preparando para lidar com estes novos profissionais?

\section{Considerações Finais}

A modalidade de EaD tem crescido rapidamente no país e o curso de Serviço Social tem apresentado grande procura, levando pesquisadores da área a investigarem a modalidade e apontando suas principais fragilidades, como a ausência do tripé ensino-pesquisa-extensão e as irregularidades observadas pelos órgãos de físcalização em relação à supervisão de estágio, além da dificuldade para realizar pesquisa com os sujeitos envolvidos nesta modalidade de ensino, tanto com os trabalhadores como os estudantes.

Por meio das entrevistas, pudemos observar que o ensino a distância tem se constituído uma forma massificada de ensino - as tarefas são divididas e cada trabalhador fica com uma parte do processo, o que ocasiona tanto a alienação do trabalho, como a fragmentação do processo de ensino-aprendizagem.

Esse cenário demonstra um retrocesso em relação ao que a categoria construiu nos últimos vinte anos, com a formulação das diretrizes curriculares que representam a direção social crítica para a formação que proporcione aos educandos a possibilidade de apreensão do processo histórico como totalidade, a apreensão das particularidades da constituição e do desenvolvimento do Serviço Social e do capitalismo no Brasil, do significado social da profissão, das demandas consolidadas e emergentes postas à profissão.

Assim como indicou um dos entrevistados na pesquisa, as dificuldades que já vinham sendo apontadas pela ABEPSS de precarização da formação em Serviço Social diante da mercantilização e precarização do ensino superior no Brasil aparecem acentuadas na modalidade a distância.

Também verificamos que, embora as diretrizes curriculares da ABEPSS tenham sido definidas como parâmetro para análise das práticas na modalidade de $\mathrm{EaD}$, os resultados da pesquisa dão um indicativo que nem mesmo as diretrizes curriculares do MEC estão sendo cumpridas integralmente.

Como todo processo investigativo não se esgota em si mesmo, assim como não responde a todas as indagações suscitadas, consideramos importante que as entidades representativas da profissão e os Programas de Pós-Graduação em Serviço Social ampliem e fomentem as pesquisas em relação a modalidade EaD para que a formação construída pela ABEPSS possa ser garantida.

\section{Referências}

ALMEIDA, Sérgio; WOLFF, Simone. Novas tecnologias e o trabalho docente na modalidade ensino à distância. VI Seminário do Trabalho, 2008, Marília. Anais. Disponível em: http://www.estudosdotrabalho.org/anais6seminariodotrabalho/sergioantunesdealmeida.pdf. Acesso em: 08 de maio de 2019.

ASSOCIAÇÃO BRASILEIRA DE ENSINO E PESQUISA EM SERVIÇO SOCIAL (ABEPSS). Diretrizes Gerais para o curso de Serviço Social. Rio de Janeiro, 1996.

BANCO MUNDIAL. La enseñanza superior: las lecciones derivadas de la experiencia. Washington, 1994. Disponível em: http:// www.bancomundial.org.br.Acesso em: 10 maio 2019.

BRASIL. Constituição da República Federativa do Brasil. Brasília, DF: Senado Federal, 1998.

BRASIL. Lei $n$. 9394, 20 de dezembro de 1996.Estabelece as diretrizes e bases da educação nacional. Disponível em: http:// www.planalto.gov.br/ccivil_03/leis/19394.htm. Acesso em: 15 maio 2019.

BRASIL. Lei n. 8.662/93 de regulamentação da profissão. Código de ética do/a assistente social.9. ed. rev. e atual. [Brasília]: Conselho Federal de Serviço Social, [2011]. 
BRASIL. Lei n.13.005, de 25 de junho de 2014. Aprova o Plano Nacional de Educação - PNE e dá outras providências. Diário Oficial da União, Brasília, DF, 26 jun. 2014.

CARDOSO, Franci Gomes. As novas diretrizes curriculares para a formação profissional do Assistente Social. Temporalis, Brasília, v. 1, n. 2, p. 7-17, 2000.

CONSELHO FEDERAL DE SERVIÇO SOCIAL (CFESS). Sobre a incompatibilidade entre graduação a distância e serviço social. Brasília, 2014.v.1.

CONSELHO FEDERAL DE SERVIÇO SOCIAL (CFESS). Sobre a incompatibilidade entre graduação a distância e serviço social. Brasília, 2015. v. 2.

LIMA, Kátia. Contra-reforma na Educação Superior: de FHC à Lula. São Paulo: Xamã, 2007.

LIMA, Katia Regina de Souza; PEREIRA, Larissa Dahmer. Contra-reforma da educação superior brasileira: impactos na formação profissional em Serviço Social. Sociedade em Debate, Pelotas, v. 15, n. 1, p. 31- 50, jan./jan. 2009.

LEWGOY, Alzira Maria Baptista. Supervisão de estágio em Serviço Social: desafios para a formação e o exercício profissional. 2. ed. São Paulo: Cortez, 2010.

LEWGOY, Alzira Maria Baptista; MACIEL, Ana Lúcia Suárez. O Projeto de Formação em Serviço Social: Análise da sua trajetória histórica no período 1996 a 2016. Temporalis, Brasília, v. 16, n. 32, p. 23-49, jul./dez. 2016.

PEREIRA, Larissa Dahmer. Expansão dos cursos de Serviço Social na modalidade EaD: direito à educação ou discriminação educacional? SER Social, Brasília, v.14, n.30, p.30-49, 2012.

PETERS, Otto. Didática do ensino a distância. São Leopoldo: Editora UNISINOS, 2006.

PORTES, Lorena Ferreira. Os Fundamentos ideopolíticos da direção social que orienta a formação profissional em Serviço Social no Brasil: a apreensão de assistentes sociais docentes que atuam em escolas paranaenses. 2016. Tese (Doutorado em Serviço Social e Política Social) -Programa de Pós-Graduação em Serviço Social e Política Social, Universidade Estadual de Londrina, Londrina, 2016. SGUISSARDI, Valdemar; SILVA JR, J. R. Reconfiguração da educação superior no Brasil e redefinição das esferas públicas e privada nos 90. Revista Brasileira de Educação, São Paulo, v. 10, p. 33-57, 1999.

SGUISSARDI, Valdemar. Educação Superior no Brasil. Democratização ou massificação mercantil? Revista Educação e Sociedade. V. 36, n. 133, p. 867-889, 2015. Disponível em: http://www.scielo.br/pdf/es/v36n133/1678-4626-es-36-133-00867.pdf. Acesso em: 25 jun. 2019.

\section{Nota}

1 Utilizaremos o artigo definido o com o intuito de não identificar os sujeitos que fizeram parte da pesquisa e facilitar a leitura.

\section{Patrícia Palmeira Gonçalves}

pati_palmeira@hotmail.com

Mestrado pelo Programa de Pós-Graduação em Serviço Social e Política Social da Universidade Estadual de Londrina (UEL)

Assistente Social na Prefeitura Municipal de Londrina

\section{PML/ PR}

Av. Duque de Caxias, 635 - Jardim Mazzei II

Londrina - Paraná - Brasil

CEP: 86015-901

\section{Claudia Neves da Silva}

claudianeves@sercomtel.com.br

Doutorado Pelo Programa de Pós-Graduação em História da Universidade Estadual Paulista (UNESP/Assis). Professora Associada do Departamento de Serviço Social da Universidade Estadual de Londrina (UEL)

\section{UEL}

Rodovia Celso Garcia Cid/ PR445 km 380 - Campus Universitário

Londrina - Paraná - Brasil

CEP: 86.057-970 
Agência financiadora

Não se aplica.

\section{Contribuições das autoras}

Patrícia Palmeira Gonçalves: desenvolveu a pesquisa que resultou na Dissertação de Mestrado.

Claudia Neves da Silva: orientou a pesquisa e estruturou o artigo.

Aprovação por Comitê de Ética e consentimento para participação

Não se aplica.
Consentimento para publicação

Não se aplica.

\section{Conflito de interesses}

Não há conflito de interesses. 